\title{
Effects of Cherry Leaf Spot on Photosynthesis in Tart Cherry 'Montmorency' Foliage
}

\author{
B. R. Gruber, E. L. Kruger, and P. S. McManus
}

First author: Horticultural Sciences Department, IRREC, IFAS, University of Florida, Fort Pierce 34945; second author: Department of Forest and Wildlife Ecology, and third author: Department of Plant Pathology, University of Wisconsin, Madison 53706. Accepted for publication 28 February 2012.

\section{ABSTRACT}

Gruber, B. R., Kruger, E. L., and McManus, P. S. 2012. Effects of cherry leaf spot on photosynthesis in tart cherry 'Montmorency' foliage. Phytopathology 102:656-661.

Results described here span a total of three field seasons and quantitatively depict the effects of an economically important fungal pathogen (Blumeriella jaapii) on tart cherry (Prunus cerasus 'Montmorency') leaf physiology. For the first time, leaf photosynthesis, stomatal conductance $\left(g_{\mathrm{s}}\right)$, maximum ribulose-1,5-bisphosphate carboxylation rate $\left(V_{\mathrm{cmax}}\right)$, and maximum electron transport $\left(J_{\max }\right)$ were measured as functions of visible cherry leaf spot disease (CLS) severity. Defined as the proportion of chlorotic and necrotic tissue per leaf, CLS severity was estimated from leaves of mature 'Montmorency' trees in 2007, 2008, and 2009. Briefly, as visible disease severity increased, all of the leaf-level physiological parameters decreased significantly $(P<0.01)$ and disproportionately. Thus, the effects of visible symptoms on leaf photosynthetic metabolic function encroached upon asymptomatic tissue as well. Impairment of photosynthetic metabolism in 'Montmorency' tart cherry leaves due to CLS appears to be mediated through disproportionately large perturbations in $g_{s}, V_{\text {cmax }}$, and $J_{\max }$. These findings offer a new perspective on the amount of damage that this serious disease can inflict.

Additional keywords: fungicide, gas exchange.
Growth and production of tart cherry (Prunus cerasus L.) in the Great Lakes region of the United States is threatened by cherry leaf spot disease (CLS), caused by Blumeriella jaapii (Rehm) Arx (anamorph Phloeosporella padi (Lib.) Arx) (11). After ascospores or conidia germinate on the abaxial leaf surface and enter through stomata (12), hyphae grow throughout intercellular spaces of the mesophyll and haustoria penetrate cell walls (7). Diseased foliage presents chlorotic and necrotic lesions with acervuli $(11,26)$. Affected leaves can drop prematurely from the canopy, adversely affecting fruit quality and yield in the current year (11) as well as bloom and fruit set in the following year (9). Howell and Stackhouse (9) reported that tart cherry trees prematurely defoliated by CLS had delayed flower bud acclimation to low temperatures in the winter and hastened deacclimation in the spring, compared with trees defoliated naturally by frost. This resulted in decreased flower bloom and fruit set on CLS-affected trees for 2 years. Those authors speculated that premature defoliation caused by CLS depleted carbohydrate reserves needed for seasonal acclimation and deacclimation of flower buds.

Tart cherry productivity is dependent, in part, upon accumulated absorbed solar radiation by visibly healthy leaf area during the growing season (4). Waggoner and Berger (27) proposed the use of healthy leaf-area absorption of solar radiation to predict crop yield during disease epidemics. However, Johnson (10) and Lopes and Berger (16) noted that some pathogens alter a leaf's ability to absorb solar radiation while others alter the efficiency of its use in the absence of visible symptoms. The latter type of impairment can lead to greater estimated losses of photosynthesis because such effects on asymptomatic tissues are not accounted

Corresponding author: B. R. Gruber; E-mail address: bgruber@ufl.edu

http://dx.doi.org/10.1094/PHYTO-12-11-0334

(c) 2012 The American Phytopathological Society for when strictly integrating the absorption of healthy leaf area $(10,16)$. Bastiaans (2) introduced a method to quantify photosynthetic impairment of asymptomatic tissue in relation to a leaf's visible disease severity. This method assumes that photosynthetic capacity within visibly damaged portions of a leaf is nil. The visual lesions are a part of a larger "virtual" lesion that encroaches upon asymptomatic leaf tissues, and photosynthetic capacity within the entire "virtual" lesion, despite appearing healthy, is potentially impaired (2). Adopting this methodology has led to detailed quantifications of the effects of fungal pathogens on leaf photosynthesis in several perennial food and fiber crop systems $(3,19,23,25)$. Following such an approach could lead to a better understanding of the extent of injury from CLS that tart cherry leaves can sustain before photosynthesis is impaired.

Following symptom development from B. jaapii infection, photosynthesis of tart cherry is potentially jeopardized by disruption of multiple processes. Neiderleitner and Knoppik (20) investigated mechanisms by which $B$. jaapii infection can reduce photosynthesis and concluded that maximum rates of ribulose1,5-bisphosphate carboxylation $\left(V_{\mathrm{cmax}}\right)$ and photosynthetic electron transport $\left(J_{\max }\right)$ were disrupted more than stomatal function in potted trees that were inoculated in a greenhouse. However, those authors did not assess the extent of photosynthetic loss in relation to severity of CLS symptoms in an orchard where infection occurs naturally throughout the season. Quantifying photosynthetic loss due to CLS symptoms would aid the understanding of the impacts of this disease on tart cherry growth and yield. The purpose of this work was to monitor the effects of CLS on leaf photosynthetic processes in mature, orchard-grown cherry trees. Specific aims were to (i) compare, at various time points, net $\mathrm{CO}_{2}$ assimilation $(A)$ and stomatal conductance $\left(g_{s}\right)$ of tart cherry leaves sprayed with fungicides used to manage CLS, or not sprayed; (ii) assess $A$ and $g_{\mathrm{s}}$ in asymptomatic leaf tissue of diseased leaves; and (iii) quantify the effects of CLS symptoms on key facets of photosynthetic metabolism ( $V_{\mathrm{cmax}}$ and $\left.J_{\max }\right)$. 


\section{MATERIALS AND METHODS}

Field site and fungicide applications. Experiments were carried out in 2007, 2008, and 2009 at the University of WisconsinMadison Peninsular Agricultural Research Station (UWPARS) in Sturgeon Bay, WI $\left(44^{\circ} \mathrm{N}, 87^{\circ} \mathrm{W}\right)$. The experimental orchard was planted in 1995 and consisted of tart cherry trees (Prunus cerasus 'Montmorency' on $P$. mahaleb L. rootstock) spaced $7.7 \mathrm{~m}$ within rows and $7.7 \mathrm{~m}$ between rows. All trees within the experimental orchard received uniform caretaking, including drip irrigation, annual application of soluble fertilizer, and winter pruning during all years of research.

Descriptions of the fungicide programs implemented at the UWPARS orchard in all years have been described previously (6) and details relevant to the current study are provided in Table 1 . In 2007, the orchard was divided into three plots, and each plot was randomly assigned to one of the following fungicide programs: (i) nonsprayed control, (ii) standard program composed of synthetic fungicides only, or (iii) integrated copper program composed of synthetic and copper-based fungicides. In 2008 and 2009, the orchard was divided into six plots and each fungicide program was replicated twice (i.e., $n=2$ ) in a completely randomized design. Between 2008 and 2009, the three fungicide programs were rerandomized. Fungicides were applied under calm conditions in a volume of 560 liter ha $^{-1}$ with an airblast sprayer. Applications commenced approximately at the time of petal fall and continued every 7 to 15 days. This field site was used to assess the effects of copper-based fungicides on fruit quality (6). However, because determining the effects of copper on photosynthesis was not a goal of the current study, only the control and standard synthetic fungicide treatment plots were used for this work.

Measurements of leaf gas exchange. In 2007, 2008, and 2009, light-saturated rates of leaf net photosynthesis $\left(A, \mu \mathrm{mol} \mathrm{CO} \mathrm{CO}^{-2} \mathrm{~s}^{-1}\right)$ and stomatal conductance $\left(g_{\mathrm{s}}, \mathrm{mol} \mathrm{H}_{2} \mathrm{O} \mathrm{m}^{-2} \mathrm{~s}^{-1}\right)$ were measured at ambient $\mathrm{CO}_{2}$ partial pressure with a portable system (LI-6400; LiCor Inc., Lincoln, NE). In 2007, $A$ and $g_{\text {s }}$ were measured on 28 June, 23 July, 14 August, and 1 September. Five trees each from the nonsprayed and standard fungicide programs were arbitrarily selected and four sun-exposed, terminal shoots were arbitrarily selected per tree. One fully expanded leaf per shoot was placed in the cuvette sample chamber $\left(6 \mathrm{~cm}^{2}\right)$. The $\mathrm{CO}_{2}$ partial pressure inside the cuvette reference chamber $\left(C_{\mathrm{a}}\right)$ was set to $38 \mathrm{~Pa}$ and photosynthetic photon flux (PPF) (provided by a blue-red LED lamp) was set to $2,000 \mu \mathrm{mol} \mathrm{m} \mathrm{m}^{-2} \mathrm{~s}^{-1}$.

In 2008, gas exchange was measured on 5 July, 6 August, 21 August, and 7 September. In 2009, gas exchange was measured on 17 July and 27 August. In both 2008 and 2009, three trees from each replicate plot were arbitrarily selected for gas exchange measurements and were repeatedly sampled throughout the season. On each sample date in 2008, three sun-exposed, terminal shoots were selected per tree and one fully expanded leaf per shoot was selected for gas exchange measurement. On each sample date in 2009, six sun-exposed, terminal shoots of the current year's growth were selected per tree and one fully expanded leaf per shoot was selected for gas exchange measurement. Trees (2007) and plots of trees (2008 and 2009) in each fungicide program were blocked by the time of measurement to account for diurnal trends in leaf microenvironment and physiological status. Ambient conditions in the cuvette sample chamber and timing of measurements in 2008 and 2009 were the same as in 2007. Leaf temperature inside the cuvette sample chamber was 22 to $28^{\circ} \mathrm{C}$ and measurements were conducted between 0900 and $1300 \mathrm{~h}$ Central Daylight Time across all sampling dates in all years.

Photosynthetic $\mathbf{C O}_{2}$-response curves. On 26 August 2007, one sunlit, fully expanded leaf, arbitrarily chosen from each tree in the nonsprayed control and standard fungicide programs, was subjected to stepwise measurements of $A$ at descending $C_{\mathrm{a}}$ of 46 to $37,25,15,10$, and $5 \mathrm{~Pa}$, and then ascending $C_{\mathrm{a}}$ of $58,66,81$, 91, 111, and $152 \mathrm{~Pa}$. On 13 August 2008, a leaf on each of two arbitrarily chosen trees per plot from the nonsprayed control and standard fungicide programs was subjected to stepwise measurements of $A$ at descending $C_{\mathrm{a}}$ of 41 to 25,15 , and $8 \mathrm{~Pa}$, and then ascending $C_{\mathrm{a}}$ of 61 to 101 and $142 \mathrm{~Pa}$. This was repeated on 26 August 2009, except that the lowest measurement $C_{\mathrm{a}}$ was $11 \mathrm{~Pa}$. All measurements were conducted at a PPF of $2,000 \mu \mathrm{mol} \mathrm{m} \mathrm{m}^{-2} \mathrm{~s}^{-1}$. Leaf temperature inside the cuvette chamber was 25 to $28^{\circ} \mathrm{C}$ across all years. Based on these data, maximum rates of $V_{\mathrm{cmax}}$ $\left(\mu \mathrm{mol} \mathrm{m} \mathrm{m}^{-2} \mathrm{~s}^{-1}\right)$ and $J_{\max }\left(\mu \mathrm{mol} \mathrm{m} \mathrm{m}^{-2} \mathrm{~s}^{-1}\right)$, as well as nonphotorespiratory respiration $\left(R_{\mathrm{d}}\right)\left(\mu \mathrm{mol} \mathrm{m} \mathrm{m}^{-2} \mathrm{~s}^{-1}\right)$, were estimated for individual leaves using models described by Long and Bernacchi (15).

Digital leaf image analysis. Severity of leaf damage caused by symptoms and signs of CLS was defined as the proportion of leaf area exhibiting symptoms or signs and was quantified as described previously $(3,5,6)$ and as follows. In each year, for the nonsprayed program only, leaves were harvested following gas exchange measurements, and their images were digitized using a flatbed scanner (Epson Perfection 2480 PHOTO; Epson America Inc., Long Beach, CA) at 400 dpi resolution. ASSESS image analysis software (v.1.0; American Phytopathological Society, St. Paul, MN) was used to quantify the proportion of pixels affected by chlorosis, necrosis, and sporulating acervuli commensurate with CLS symptoms and signs on the abaxial and adaxial surfaces of nonsprayed leaves. Only the portion of leaf surface $\left(6 \mathrm{~cm}^{2}\right)$ that was placed within the gas exchange cuvette (marked at the time of measurement) was assessed for severity of CLS signs and symptoms. The proportions of pixels reflecting CLS signs and symptoms from the abaxial and adaxial surfaces were averaged.

TABLE 1. Standard fungicide program applied to 'Montmorency' tart cherry at Sturgeon Bay, WI

\begin{tabular}{|c|c|c|}
\hline Application date ${ }^{\mathrm{a}}$ & Active ingredient ${ }^{\mathrm{b}}$ & Rate $\left(\mathrm{g} \mathrm{ha}^{-1}\right)^{\mathrm{c}}$ \\
\hline \multicolumn{3}{|l|}{2007} \\
\hline 15 May & Chlorothalonil & 3,468 \\
\hline 30 May & Chlorothalonil & 3,468 \\
\hline 13 June & Pyraclostrobin+boscalid & $126+247$ \\
\hline 22 June & Fenbuconazole & 105 \\
\hline 6 July & Pyraclostrobin+boscalid & $107+212$ \\
\hline 16 July & Tebuconazole & 189 \\
\hline 21 August & Chlorothalonil & 3,468 \\
\hline \multicolumn{3}{|l|}{2008} \\
\hline 28 May & Chlorothalonil & 2,626 \\
\hline 10 June & Chlorothalonil & 2,626 \\
\hline 19 June & Fenbuconazole & 105 \\
\hline 26 June & Fenbuconazole & 105 \\
\hline 7 July & Pyraclostrobin+boscalid & $94+185$ \\
\hline 21 July & Tebuconazole & 252 \\
\hline 8 August & Chlorothalonil & 3,362 \\
\hline \multicolumn{3}{|l|}{2009} \\
\hline 29 May & Chlorothalonil & 2,689 \\
\hline 6 June & Chlorothalonil & 2,606 \\
\hline 15 June & Pyraclostrobin+boscalid & $94+185$ \\
\hline 2 July & Trifloxystrobin & 110 \\
\hline 14 July & Fenbuconazole & 105 \\
\hline 27 July $^{\mathrm{d}}$ & Pyraclostrobin+boscalid & $94+185$ \\
\hline
\end{tabular}

a Only one active ingredient per fungicide program was applied on each date, unless noted otherwise.

${ }^{\mathrm{b}}$ Fungicide common names, brands, formulations used, and manufacturer: chlorothalonil (Echo 720, Sipcam Agro USA, Inc., Roswell, GA in 2007, 2008, and 2009 and Equus 720 SST, Makhteshim Agan North America, Inc., Raleigh, NC in 2009); fenbuconazole (Indar 75WSP, Dow AgroSciences, LLC, Indianapolis, IN); pyraclostrobin+boscalid (Pristine, BASF Corp., Research Triangle Park, NC); tebuconazole (Elite 45DF, Bayer CropScience, Research Triangle Park, NC); and trifloxystrobin (Gem 500SC, Bayer CropScience).

${ }^{c}$ Gallons per hectare.

${ }^{d}$ A postharvest application of chlorothalonil had not yet been applied by the time of the study's conclusion. 
Statistical analyses. A linear mixed-model approach to repeated measures analysis was used to determine differences in means of $A$ and $g_{\text {s }}$ between sprayed and nonsprayed treatments each sample date in 2008 and 2009. Repeated measures analyses were performed using PROC MIXED in SAS (v. 9.2; SAS Institute Inc., Cary, NC). Data from 2008 and 2009 were analyzed separately. Sample date, fungicide program, and their interaction were considered fixed effects. Leaf values of $A$ and $g_{\mathrm{s}}$ for both fungicide programs were averaged to the tree-level, then to the plot level, and plots were defined as individual experimental units $(n=2)$ The plot(fungicide) nested variable was used as the repeated effect in all models to assess the covariance of $A$ and $g_{\text {s }}$ among sample dates. In addition, the plot(fungicide) nested variable was added as a random effect to model between-plot variance (14). Candidate covariance structures were chosen using Akaike's Information Criterion (AIC), and the Kenward-Roger correction for degrees of freedom was used in all repeated measures analyses (14). Plot-level measurements of $A$ and $g_{\text {s }}$ were blocked by the time of day in which they were taken and "time" was added as a random block effect to all models. Tukey-adjusted multiple pairwise comparisons of all sample date-fungicide program combinations were used to separate means, when appropriate. The repeated measures models of 2008 mean $A$ and $g_{\text {s }}$ were both fitted with a first-order heterogeneous autoregressive covariance, as indicated by AIC values. The repeated measures models of 2009 mean $A$ and $g_{s}$ were both fitted with compound symmetry covariance, as indicated by AIC values, but the plot(fungicide) random effect to model between-plot variance was not included in the model, following the recommendation of Littell et al. (14).

Nonlinear regression was used to quantify the relationship between gas exchange parameters and CLS severity (proportion of leaf surface exhibiting symptoms and signs). Nonlinear regressions were evaluated using the nls and nlme libraries (22) of R (R Foundation for Statistical Computing, Vienna). Individual leaves sampled from the nonsprayed fungicide program were defined as experimental units for all regression analyses. Measurements of $A$ and $g_{\mathrm{s}}$ at a $C_{\mathrm{a}}$ of $38 \mathrm{~Pa}$ on 14 August 2007, 6 August 2008, and 27 August 2009 were used as dependent variables in one analysis. In addition, estimates of $V_{\mathrm{cmax}}, J_{\max }$, and $R_{\mathrm{d}}$ obtained from the photosynthetic $\mathrm{CO}_{2}$-response curves were used as dependent variables in nonlinear regression to quantify the effects of CLS severity. For each of the gas exchange parameters, data from all years were pooled. Nonlinear equations took the form first proposed by Bastiaans (2) by which photosynthetic impairment is quantified as $y=(1-x)^{\beta}$, where $y$ is a measurement of relative photosynthetic performance, $x$ is a proportion of leaf surface affected by visible lesions, and $\beta$ is an estimated regression coefficient and was treated as a fixed effect. Values of $\beta$ significantly $>1$ have been interpreted as photosynthetic impairment of asymptomatic leaf tissue beyond the borders of visible damage $(3,16)$. These relationships, however, are pre- dicated on the photosynthetic capacity of visibly healthy leaves, because the dependent variable is a relative measure of photosynthesis (2,3). Synthetic fungicides used for CLS management were not found to perturb foliar gas exchange in tart cherry, compared with a water-sprayed control (5). Thus, mean values of gas exchange parameters from the standard fungicide program were considered healthy leaf values in the current study to obtain relative values described in Bastiaans' (2) model. In other words, individual values of $A$ and $g_{\mathrm{s}}$ or $V_{\mathrm{cmax}}, J_{\max }$, and $R_{\mathrm{d}}$ from leaves sampled from the nonsprayed fungicide program were divided by mean values of $A$ and $g_{\mathrm{s}}$ or $V_{\mathrm{cmax}}, J_{\max }$, and $R_{\mathrm{d}}$ from leaves in the standard fungicide program (Table 2), from the same date, in each year. Student's $t$ tests (one-tailed) were used to determine if the observed values of $\beta$ were significantly $>1$.

Because data in the nonlinear regression analyses were pooled, random block effects for the "year" variable and the "plot" variable were added to the $\beta$ regression coefficient. Including these variables did not improve AIC values or increase precision (i.e., decrease the $95 \%$ confidence interval $[\mathrm{CI}]$ ) of the estimate and were removed. The final fitted models for relative $A$ and $g_{\text {s }}$ measured on 14 August 2007, 6 August 2008, and 27 August 2009 included adding the "tree" random variable to the $\beta$ regression coefficient and used a constant-power function to model residual variance heterogeneity. However, no random effects for the tree variable were added to the $\beta$ regression coefficient for models evaluating gas exchange parameters derived from the photosynthetic $\mathrm{CO}_{2}$-response curves because one leaf per tree was sampled.

\section{RESULTS}

Effect of fungicide program on mean $\boldsymbol{A}$ and $\boldsymbol{g}_{\mathrm{s}}$. Leaves collected from the nonsprayed trees did not have visible CLS symptoms on the first sample date in any year (28 June 2007, 5 July 2008, or 17 July 2009) but did have symptoms on later dates (Fig. 1, CLS severity). Leaves sampled from the standard fungicide program never displayed CLS symptoms during the study (data not shown).

In 2008, there was no interacting effect $\left(\mathrm{F}_{3,1}=46.44 ; P=\right.$ 0.1074 ) between sample date and fungicide program on mean $A$ (Fig. 1) but there was an interacting effect between sample date and fungicide program $\left(\mathrm{F}_{3,1.19}=225.09 ; P=0.0302\right)$ on mean $g_{s}$. However, Tukey-adjusted multiple pairwise comparisons of all sample date-fungicide program combinations did not reveal any dates in 2008 in which mean $g_{s}$ significantly differed between the two fungicide programs (Fig. 1). In 2009, there was no interacting effect between sample date and fungicide program on mean $A$ $\left(\mathrm{F}_{1,2}=0.71 ; P=0.4890\right)$ or mean $g_{\mathrm{s}}\left(\mathrm{F}_{1,1}=0.21 ; P=0.7292\right)$ (Fig. 1).

Effects of CLS disease severity on leaf gas exchange. Mean $A$ and $g_{\mathrm{s}}$ at a $C_{\mathrm{a}}$ of $38 \mathrm{~Pa}$ (14 August 2007, 6 August 2008, and 27 August 2009) in healthy appearing leaves from the standard

TABLE 2. Leaf-level parameters estimated from the standard fungicide program ${ }^{\mathrm{a}}$

\begin{tabular}{|c|c|c|c|}
\hline Parameter & 2007 & 2008 & 2009 \\
\hline 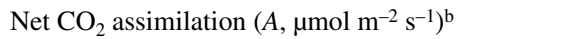 & 13.0 & 13.1 & 13.8 \\
\hline Stomatal conductance $\left(g_{\mathrm{s}}, \mathrm{mol} \mathrm{m}^{-2} \mathrm{~s}^{-1}\right)^{\mathrm{b}}$ & 0.25 & 0.22 & 0.22 \\
\hline Maximum carboxylation rate $\left(V_{\mathrm{cmax}}, \mu \mathrm{mol} \mathrm{m} \mathrm{m}^{-2} \mathrm{~s}^{-1}\right)^{\mathrm{c}}$ & 69.1 & 69.0 & 74.5 \\
\hline Maximum electron transport $\left(J_{\max }, \mu \mathrm{mol} \mathrm{m} \mathrm{m}^{-2} \mathrm{~s}^{-1}\right)^{\mathrm{c}}$ & 205.1 & 237.2 & 225.8 \\
\hline Nonphotorespiratory respiration $\left(R_{\mathrm{d}}, \mu \mathrm{mol} \mathrm{m} \mathrm{m}^{-2} \mathrm{~s}^{-1}\right)^{\mathrm{c}}$ & 5.3 & 4.3 & 4.3 \\
\hline
\end{tabular}

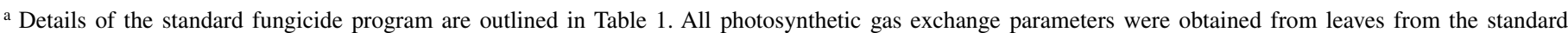
fungicide program by averaging over all leaves on a given sample date. These leaves were used as apparently asymptomatic controls to calculate relative gas exchange parameters compared with leaves from the nonsprayed program. All leaves sampled from the standard synthetic program lacked visible cherry leaf spot disease damage.

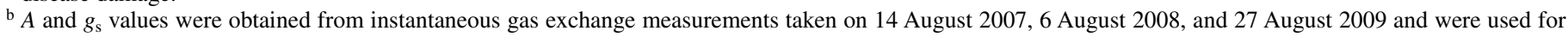
relative gas exchange parameters in Figure 2.

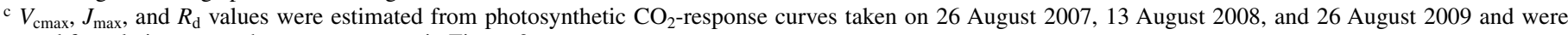
used for relative gas exchange parameters in Figure 3. 
fungicide program are summarized in Table 2. These means were used to calculate relative values of $A$ and $g_{\mathrm{s}}$ for nonsprayed leaves measured on the same sample date. Severity of CLS symptoms and signs on nonsprayed leaves was 0 to $96.6 \%$ (median $=1.1 \%$ ). Values of relative $A\left(|\mathrm{t}|_{54}=3.78 ; P<0.001\right)$ and relative $g_{\mathrm{s}}\left(|\mathrm{t}|_{54}=\right.$ $6.57 ; P<0.001)$ decreased significantly with increasing severity of CLS symptoms and signs (Fig. 2). The point estimate of the $\beta$ regression coefficient for relative $g_{\text {s }}$ was $73 \%$ larger than that of the one observed for relative $A$, indicating that CLS may more negatively affect stomatal conductance than net $\mathrm{CO}_{2}$ assimilation. Indeed, the $95 \%$ CIs for the two $\beta$ regression coefficients do not overlap, indicating that these point estimates differ significantly (Fig. 2).

Mean $V_{\text {cmax }}, J_{\max }$, and $R_{\mathrm{d}}$ (26 August 2007, 13 August 2008, and 26 August 2009) estimated from the photosynthetic $\mathrm{CO}_{2}$-response curves conducted on leaves from the standard fungicide program are summarized in Table 2. These means were used to calculate relative values of $V_{\mathrm{cmax}}, J_{\max }$, and $R_{\mathrm{d}}$ for nonsprayed leaves measured in the same year. Values of relative $V_{\text {cmax }}\left(\left.|t|\right|_{10}=3.53\right.$; $P=0.003)$ and relative $J_{\max }\left(|t|_{10}=3.49 ; P=0.003\right)$ decreased significantly with increasing CLS severity. Variation in relative $R_{\mathrm{d}}$ was not significantly related to CLS severity $\left(|\mathrm{t}|_{10}=0.54 ; P=\right.$ 0.30 ; data not shown). The point estimate of the $\beta$ regression coefficient for relative $J_{\max }$ was $28 \%$ larger than that of the one observed for relative $V_{\text {cmax }}$ but the $95 \%$ CIs for the two $\beta$ regression coefficients overlapped, indicating no significant difference (Fig. 3).

\section{DISCUSSION}

CLS significantly impaired photosynthetic functions in tart cherry leaves. Bastiaans' $\beta$ parameter (2) represents photosynthetic impairment of asymptomatic leaf tissue if its value is significantly $>1$. Thus, the proportion of leaf surface in which $A$ and $g_{\mathrm{s}}$ were negligible extended 6.57 and 24.11 times, respectively, beyond the visual damage (Fig. 2). Additionally, the relative effect on stomatal conductance was significantly larger (based on comparisons of $95 \%$ CIs for $\beta$ values) than the effect on net $\mathrm{CO}_{2}$ assimilation. Empirical values of $\beta$ have been categorized previously to describe modes of fungal pathogenicity $(1,3,16)$. In general, diseases caused by facultative pathogens have larger $\beta$ estimates than obligate pathogens. Compared with pathogens described in published reports, leaf damage caused by $B$. jaapii has relatively high $\beta$ values, consistent with $B$. jaapii's status as a facultative parasite. However, it should be noted that $\beta$ values are monotonic and might lead to underestimates of photosynthesis at high levels of disease severity. For example, predicted values of relative $g_{\mathrm{s}}$ were underestimated at higher levels of disease severity when using Bastiaans' model in the current study, and a similar bias was observed by Erickson et al. (3). Therefore, the current model for associating photosynthetic impairment and leaf disease severity may need to be refined to incorporate a regression coefficient that is not fixed but that varies with disease severity.

Biochemical processes determining the maximum rate of $A$ are vulnerable to perturbation following fungal infection of leaves. In
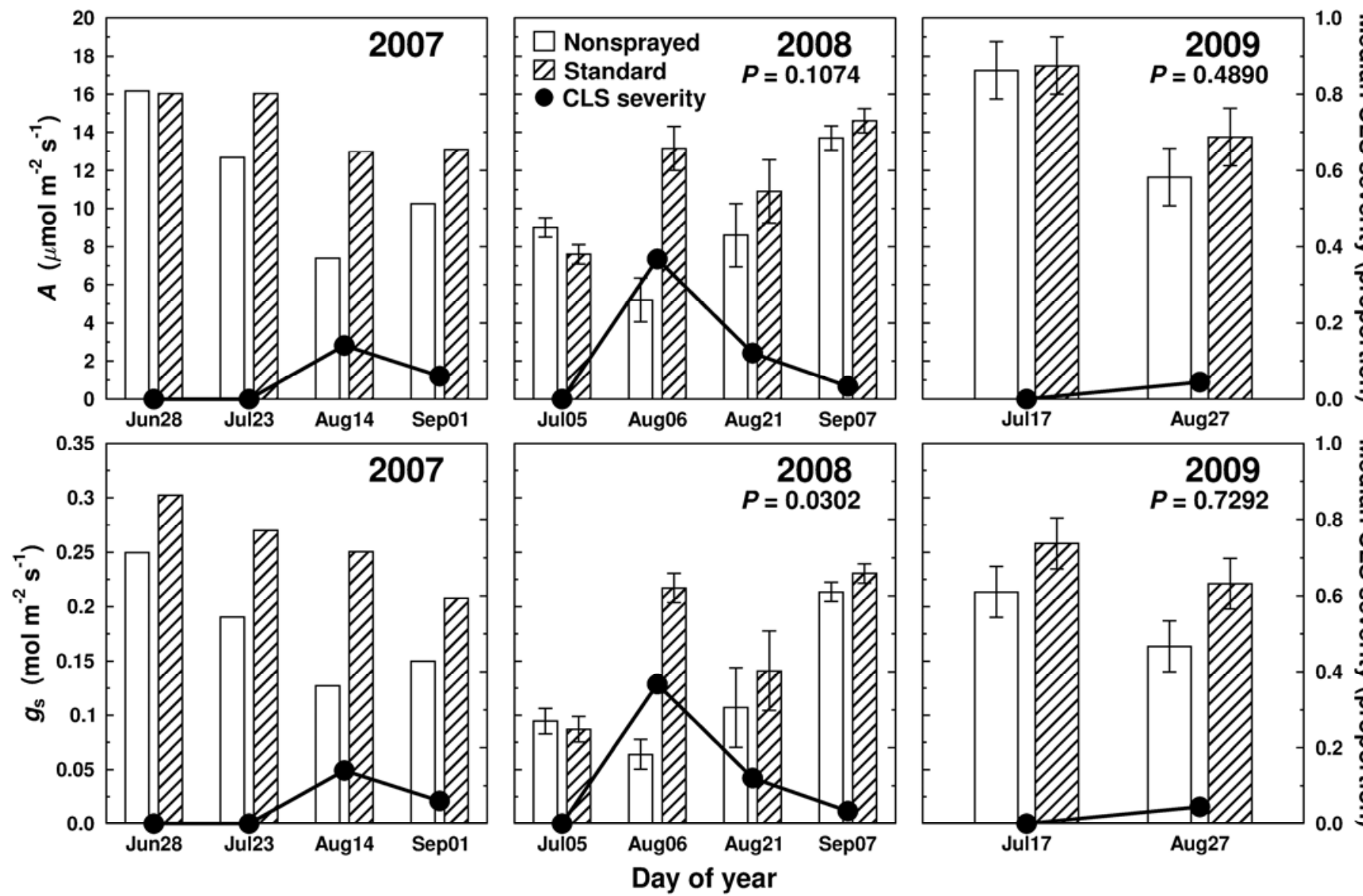

홍

Fig. 1. Effect of fungicide program on net $\mathrm{CO}_{2}$ assimilation $(A)$ and stomatal conductance $\left(g_{\mathrm{s}}\right)$ (bars corresponding to primary y-axis) and cherry leaf spot disease (CLS) severity progression in the nonsprayed program (filled circles and solid lines corresponding to secondary y-axis). Plots of trees were considered experimental units and were assigned to either the nonsprayed or standard fungicide programs. Briefly, the standard fungicide program relied on a rotation of sterol demethylation inhibitor and strobilurin chemistries. Bars are single observations (2007) and means (2008 and 2009). For each fungicide program at each date, $n=1$ (2007) and $n=2$ (2008 and 2009). Data were analyzed using repeated measures. $P$ values represent the significance of the sample date-fungicide program interaction fixed effect. Tukey-adjusted multiple pairwise comparisons did not reveal any differences $(P<0.05)$ between fungicide programs at any date. Extension bars represent \pm one standard error of the mean. 
the current study, lower values of $V_{\mathrm{cmax}}$ and $J_{\max }$ of leaves sampled from the nonsprayed fungicide program were associated with more severe CLS symptoms and signs (Fig. 3). Douglas fir seedlings affected by Swiss needle cast disease have demonstrably lower values of $V_{\text {cmax }}(17)$. In addition, Niederleitner and Knoppick (20) concluded that maximum $V_{\text {cmax }}$ rate was the gas exchange parameter affected most by CLS in potted, inoculated trees. In the current investigation, CLS leaf severity did not differentially affect relative $V_{\text {cmax }}$ and $J_{\max }$. However, it is difficult to compare the current results with those of Niederleitner and Knoppick (20) because those authors did not provide measures of dispersion with their summary statistics or interval estimates with point estimates. In any case, values of $R_{\mathrm{d}}$ were not associated with CLS damage, a result similar to the conclusions of Erickson et al. (3), who studied Marssonina leaf spot of poplar. Although the exact mechanisms of photosynthetic impairment were not studied in this investigation, development of CLS symptoms and signs jeopardizes both $V_{\text {cmax }}$ and $J_{\max }$ in asymptomatic as well as visibly damaged tissue of tart cherry leaves.

The current study showed that, on average, $A$ and $g_{\text {s }}$ were numerically but not significantly lower in nonsprayed compared with sprayed trees (Fig. 1), which corroborates a trend observed previously (5). Average CLS severity at the tree and plot level was highly variable among experimental units (data not shown). In addition, averaging up from the leaf level to the tree and plot level likely resulted in a loss of precision due to a decrease in experimental units. Thus, under the conditions of our study, the negative effects of CLS on photosynthesis were generally modest at the tree and plot levels and not noticed until after fruit were harvested in late July.

Median CLS severity was estimated from a new cohort of leaves that were destructively sampled at each sampling date.
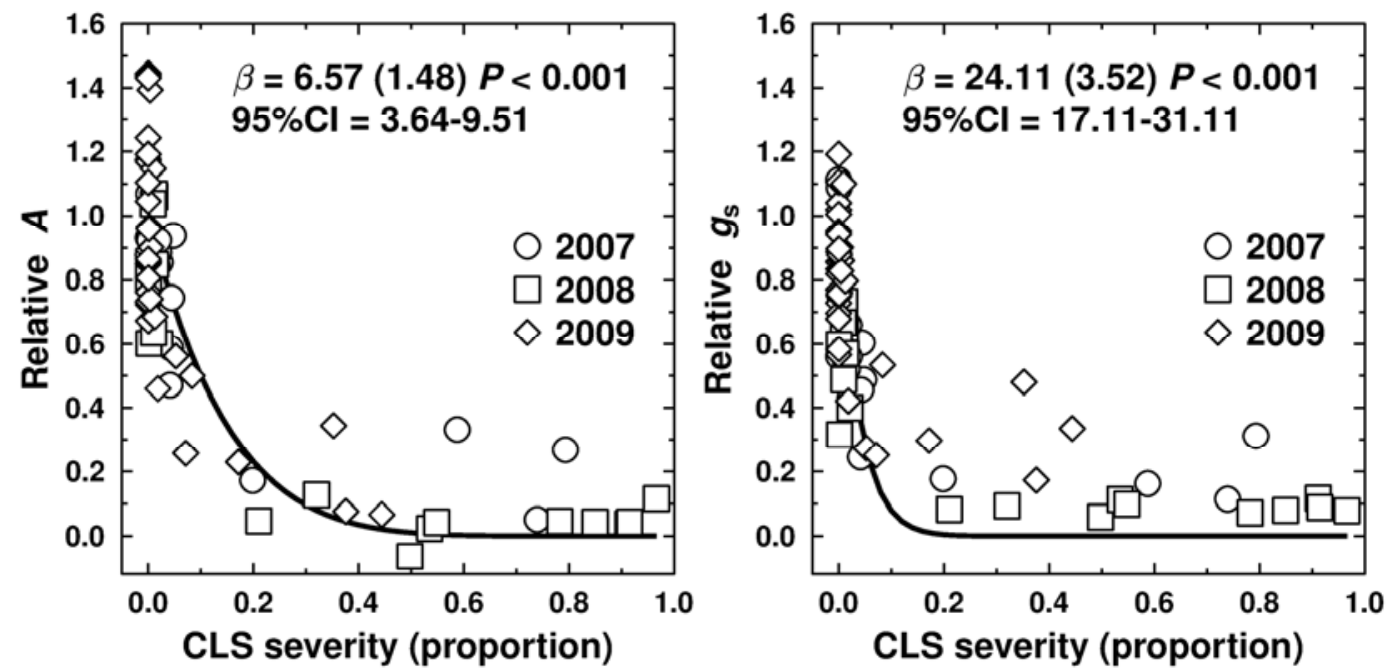

Fig. 2. Effect of cherry leaf spot disease (CLS) severity on relative net $\mathrm{CO}_{2}$ assimilation $(A)$ and stomatal conductance $\left(g_{\mathrm{s}}\right)$. The proportion of nonsprayed leaf surface affected was used to determine relationships between relative $A$ and relative $g_{\mathrm{s}}$. Relative measures of $A$ and $g_{\mathrm{s}}$ were obtained by taking individual values of $A$ and $g_{\mathrm{s}}$ from leaves sampled from the nonsprayed fungicide program and dividing them by mean values of $A$ and $g_{\mathrm{s}}$ from leaves in the standard fungicide program in each year. Leaves sampled from the standard fungicide program were asymptomatic. Each symbol represents one leaf. For 2007, 2008, and 2009, $n=$ 16,18 , and 36, respectively. Some symbols are obscured due to overlap. Values of $\beta$ ( \pm one standard error) and $95 \%$ confidence interval (CI) were estimated according to Bastiaans (2). $P$ values represent the significance of one-tailed $t$ tests evaluating: $\beta>1$. Lines represent fitted values.
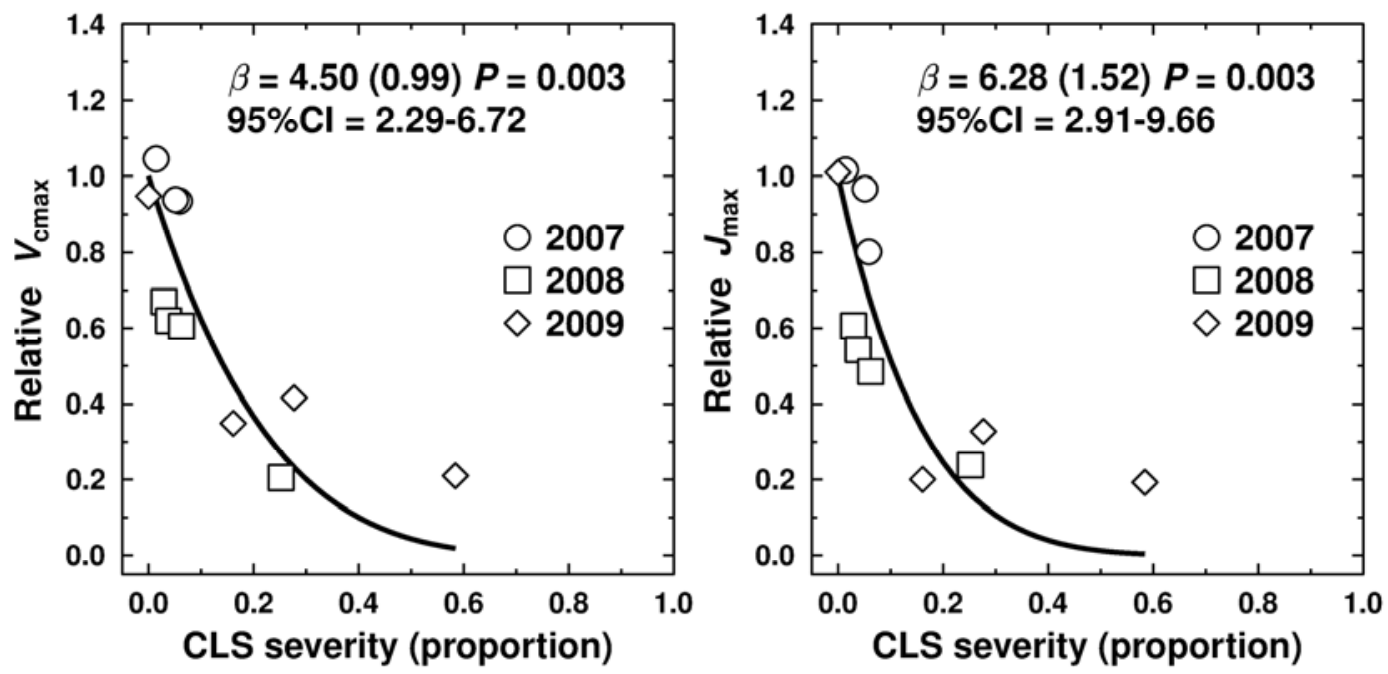

Fig. 3. Effect of cherry leaf spot disease (CLS) severity on relative maximum rate of ribulose-1,5-bisphosphate carboxylation ( $\left.V_{\text {cmax }}\right)$ and photosynthetic electron transport rate $\left(J_{\max }\right)$. The proportion of nonsprayed leaf surface affected was used to determine relationships between relative $V_{\text {cmax }}$ and relative $J_{\max }$. Relative measures of $V_{\mathrm{cmax}}$ and $J_{\max }$ were obtained by taking individual values of $V_{\mathrm{cmax}}$ and $J_{\max }$ from leaves sampled from the nonsprayed fungicide program and dividing them by mean values of $V_{\text {cmax }}$ and $J_{\max }$ from leaves in the standard fungicide program in each year. Leaves sampled from the standard fungicide program were asymptomatic. Each symbol represents one leaf. For 2007, 2008, and 2009, $n=3$, 4, and 4, respectively. Some symbols are obscured due to overlap. Values of $\beta$ ( \pm one standard error) and 95\% confidence interval (CI) were estimated according to Bastiaans (2). $P$ values for $V_{\mathrm{cmax}}$ and $J_{\max }$ represent the significance of onetailed $t$ tests evaluating: $\beta>1$. Lines represent fitted values. 
Thus, in our study, disease severity was not a cumulative measurement, and the declining values of median CLS severity in late August and early September 2007 and 2008 do not reflect an alleviation or reversal of disease severity. Instead, median CLS severity of remaining leaves was likely less severe later in the summer due to premature defoliation of damaged leaves. For instance, Ngugi and Lehman (21) reported that increased CLS symptom severity hastened the time to abscission of individual leaves. In addition, McManus et al. (18) observed that the percent change in defoliation before and after harvest (i.e., at times earlier and later in the summer) in trees afflicted with CLS was 6 to $98 \%$. Therefore, mass defoliation events of severely diseased leaves would likely affect the estimate of mean CLS severity of the tree canopy because the remaining foliage probably has less visible damage.

The current work complements previous studies devoted to investigating methods of chemical control of CLS. Copper-based fungicides historically were used to manage CLS (12). With the emergence of fungicide-resistant B. jaapii (24), research efforts have focused on integrating copper-based fungicides into spray programs to lessen the selection for resistance to synthetic fungicides $(5,6,18)$. Programs that integrated copper with synthetic fungicides were comparable with programs that relied exclusively on synthetic fungicides (18). However, discoloration of leaves following application of copper-based fungicides has been reported for various Prunus spp. $(5,6,8,12,13,18)$. In contrast to the striking reductions of $A$ and $g_{\mathrm{s}}$ associated with symptoms of CLS demonstrated in the current study (Fig. 2), similar levels of leaf copper-associated discoloration did not reduce $A$ or $g_{\mathrm{s}}$ in tart cherry leaves in late summer (5), nor was it related to reduced size or quality of fruit (6). Therefore, the application of copperbased fungicides for CLS management may result in some visually alarming foliage discoloration but the effects are negligible compared with the damage caused by the chlorotic and necrotic lesions of CLS as well as impairment of photosynthesis that extends beyond the visibly damaged leaf tissue.

In conclusion, the severity of chlorotic and necrotic lesions caused by $B$. jaapii infection was related to impairment of stomatal conductance in the remaining asymptomatic leaf tissue. Capacities of photosynthetic $V_{\mathrm{cmax}}$ and $J_{\max }$ in leaves visibly affected by CLS symptoms were also reduced disproportionately. However, specific mechanisms responsible for CLS-related photosynthetic damage and refinement of models used to quantify this damage may need to be explored.

\section{ACKNOWLEDGMENTS}

This project was funded by United States Department of Agriculture Cooperative State Research, Education and Extension Service project WIS01179. We thank M. Stasiak, R. Weidman, and B. Schauske for maintaining the orchard block; N. Keuler for statistical consulting; D. Dillaway for assistance with gas exchange analyses; L. Rens, T. Poole, and J. Franzen for assistance in the field; and two anonymous reviewers for their helpful comments and suggestions.

\section{LITERATURE CITED}

1. Bassanezi, R. B., Amorim, L., Bergamin Filho, A., Hau, B., and Berger, R. D. 2001. Accounting for photosynthetic efficiency of bean leaves with rust, angular leaf spot and anthracnose to assess crop damage. Plant Pathol. 50:443-452.

2. Bastiaans, L. 1991. Ratio between virtual and visual lesion size as a measure to describe reduction in leaf photosynthesis of rice due to leaf blast. Phytopathology 81:611-615.

3. Erickson, J. E., Stanosz, G. R., and Kruger, E. L. 2003. Photosynthetic consequences of Marssonina leaf spot differ between two poplar hybrids. New Phytol. 161:577-583.

4. Flore, J. A., and Layne, D. R. 1999. Photoassimilate production and distribution in cherry. HortScience 34:1015-1019.

5. Gruber, B. R., Davies, L. R. R., Kruger, E. L., and McManus, P. S. 2009. Effects of copper-based fungicides on foliar gas exchange in tart cherry. Plant Dis. 93:512-518.

6. Gruber, B. R., Davies, L. R. R., and McManus, P. S. 2010. A copperbased fungicide has minimal effects on tart cherry fruit quantity and quality. HortScience 45:48-53.

7. Higgins, B. B. 1914. Contribution to the life history and physiology of Cylindrosporium on stone fruits. Am. J. Bot. 1:145-173.

8. Holb, I. J., and Schnabel, G. 2005. Effect of fungicide treatment and sanitation practices on brown rot blossom blight incidence, phytotoxicity, and yield for organic sour cherry production. Plant Dis. 89:1164-1170.

9. Howell, G. S., and Stackhouse, S. S. 1973. The effect of defoliation time on acclimation and dehardening in tart cherry (Prunus cerasus L.). J. Am. Soc. Hortic. Sci. 98:132-136.

10. Johnson, K. B. 1987. Defoliation, disease, and growth: A reply. Phytopathology 77:1495-1497.

11. Jones, A. L. 1995. Cherry leaf spot. Pages 21-22 in: Compendium of Stone Fruit Diseases. J. M. Ogawa, E. I. Zehr, G. W. Bird, D. F. Ritchie, K. Uriu, and J. K. Uyemoto, eds. American Phytopathological Society, St. Paul, MN.

12. Keitt, G. W., Blodgett, E. G., Wilson, E. E., and Magie, R. O. 1937. The epidemiology and control of cherry leaf spot. Res. Bull. 132. Wisconsin Agricultural Experiment Station, Madison.

13. Lalancette, N., and MacFarland, K. A. 2007. Phytotoxicity of copperbased bactericides to peach and nectarine. Plant Dis. 91:1122-113.

14. Littell, R. C., Milliken, G. A., Stroup, W. W., Wolfinger, R. D., and Schabenberger, O. 2006. Analysis of repeated measures data. Pages 159204 in: SAS for Mixed Models, second edition. SAS Institute Inc., Cary, NC.

15. Long, S. P., and Bernacchi, C. J. 2003. Gas exchange measurements, what can they tell us about the underlying limitations to photosynthesis? Procedures and sources of error. J. Exp. Bot. 54:2393-2401.

16. Lopes, D. B., and Berger, R. D. 2001. The effects of rust and anthracnose on the photosynthetic competence of diseased bean leaves. Phytopathology 91:212-220.

17. Manter, D. K., Bond, B. J., Kavanagh, K. L., Rosso, P. H., and Filip, G. M. 2000. Pseudothecia of Swiss needle cast fungus, Phaeocryptopus gaeumannii, physically block stomata of Douglas fir, reducing $\mathrm{CO}_{2}$ assimilation. New Phytol. 148:481-491.

18. McManus, P. S., Proffer, T. J., Berardi, R., Gruber, B. R., Nugent, J. E., Ehret, G. R., Ma, Z., and G. W. Sundin. 2007. Integration of copper-based and reduced-risk fungicides for control of Blumeriella jaapii on sour cherry. Plant Dis. 91:294-300.

19. Moriondo, M., Orlandini, S., Giuntoli, A., and Bindi, M. 2005. The effect of downy and powdery mildew on grapevine (Vitis vinifera L.) leaf gas exchange. J. Phytopathol. 153:350-357.

20. Neiderleitner, S., and Knoppik, D. 1997. Effects of the cherry leaf spot pathogen Blumeriella jaapii on gas exchange before and after expression of symptoms on cherry leaves. Physiol. Mol. Plant Pathol. 51:145-153.

21. Ngugi, H. K., and Lehman, B. L. 2007. Survival analysis of time to abscission of cherry leaves infected with Blumeriella jaapii. (Abstr.) Phytopathology 97:S83.

22. Pinheiro, J. C., and Bates, D. M. 2000. Fitting nonlinear mixed-effects models. Pages 337-410 in: Mixed-Effects Models in S and S-Plus. Springer, New York.

23. Pinkard, E. A., and Mohammed, C. L. 2006. Photosynthesis of Eucalyptus globulus with Mycosphaerella leaf disease. New Phytol. 170:119-127.

24. Proffer, T. J., Berardi, R., Ma, Z., Nugent, J. E., Ehret, G. R., McManus, P. S., Jones, A. L., and Sundin, G. W. 2006. Occurrence, distribution, and polymerase chain reaction-based detection of resistance to sterol demethylation inhibitor fungicides in populations of Blumeriella jaapii in Michigan. Phytopathology 96:709-717.

25. Roloff, I., Scherm, H., and van Iersel, M. W. 2004. Photosynthesis of blueberry leaves as affected by Septoria leaf spot and abiotic leaf damage. Plant Dis. 88:397-401.

26. Stanosz, G. R. 1992. Effect of cherry leaf spot on nursery black cherry seedlings and potential benefits from control. Plant Dis. 76:602-604.

27. Waggoner, P. E., and Berger, R. D. 1987. Defoliation, disease, and growth. Phytopathology 77:393-398. 